Mitsubishi, Chugai, Teijin Pharma, Torii, Nippon Shinyaku, Pfizer. UCB. Nippon Kayaku, YL biologics, Bayer and Bristol-Meyers., Consultant for: MSD, Ayumi, AbbVie, Eisai, Ono, Astellas, Daiichi-Sankyo, Taisyo-Toyama, Takeda, TanabeMitsubishi, Chugai, Teijin Pharma, Torii, Nippon Shinyaku, Pfizer. UCB. Nippon Kayaku, YL biologics, Bayer and Bristol-Meyers., Speakers bureau: MSD, Ayumi, AbbVie, Eisai, Ono, Astellas, Daiichi-Sankyo, Taisyo-Toyama, Takeda, TanabeMitsubishi, Chugai, Teijin Pharma, Torii, Nippon Shinyaku, Pfizer. UCB. Nippon Kayaku, YL biologics, Bayer and Bristol-Meyers.

DOI: 10.1136/annrheumdis-2017-eular.3046

\section{THU0166 COMPARISON OF THE RISK OF COMORBIDITIES BETWEEN PATIENTS WITH RHEUMATOID ARTHRITIS AND DIABETES MELLITUS USING JAPANESE HEALTH INSURANCE DATABASE}

R. Sakai ${ }^{1}$, S. Kasai ${ }^{2}$, M. Tsutsumino ${ }^{1}$, H. Yamanaka ${ }^{1}$, N. Miyasaka ${ }^{3}$ M. Harigai ${ }^{1} .{ }^{1}$ Division of Epidemiology and Pharmacoepidemiology in Rheumatic Diseases, Institute of Rheumatology, Tokyo Women's Medical University; ${ }^{2}$ Department of Rheumatology, Graduate School of Medical and Dental Sciences, Tokyo Medical and Dental University; ${ }^{3}$ Tokyo Medical and Dental University, Tokyo, Japan

Background: Patients with rheumatoid arthritis (RA) have a higher risk of comorbidities such as infections ${ }^{1}$, cardiovascular diseases ${ }^{2}$, and fractures ${ }^{3}$ than general population. To understand the risk of these comorbidities in RA more precisely, it is needed to compare the risk between RA and other chronic diseases. A Dutch study ${ }^{4}$ showed that patients with RA had comparable risk of cardiovascular diseases to diabetes mellitus (DM). Because of possible racial or ethnic difference of risks of comorbidities, it is warranted to compare the risk between RA and DM in Asian countries.

Objectives: To compare risk of hospitalized infections (HIs), cardiovascular diseases and stroke (CVDs), and fractures between RA and DM cases using Japanese health insurance database.

Methods: This retrospective longitudinal population-based study was conducted using claims data provided by the Japan Medical Data Center Co., Ltd. We defined individuals as RA cases if they met all of the following: 1) had at least 6 months of continuous enrollment in the health insurance database; 2) had at least one RA diagnostic code and at least one prescription of disease-modifying antirheumatic drugs between January 2005 and December 2013; and 3) were $\geq 50$ years old (RA group, $n=3,607$ ). Among individuals who met above criteria 1) and had at least DM diagnostic code and at least one prescription of drugs for DM, but did not meet 2), we selected age- ( \pm 5 years), gender-, calendar year of the observation start, and observation length-matched DM cases at 1:3 ratio (RA: DM) (DM group, $n=10,821$ ). Each comorbidity was defined as follows: HIs, at least one ICD10 code and one prescription of drugs for infections with hospitalization; CVDs, at least one ICD10 code and one prescription of drugs or medical procedures for CVDs with hospitalization; fractures, at least one ICD10 code for fractures. We calculated incidence rates (IR) with $95 \%$ confidence interval (CI) of each comorbidity in the two groups up to 10 years and adjusted odds ratio (OR) of RA compared with DM for each comorbidity using generalized estimating equation.

Results: The median age was 58 , and $75.1 \%$ were female in the both groups. The IR [95\% Cl] of HIs, CVDs, and fractures was 2.8 [2.5-3.2]/100 patient years (PY), 9.2 [7.4-11.4]/1,000 PY, $16.7[14.2-19.6] / 1,000$ PY in the RA group, $2.8[2.6-$ 3.0]/100PY, $26.3[24.4-28.3] / 1,000 \mathrm{PY}, 10.3[9.1-11.6] / 1,000 \mathrm{PY}$ in the DM group respectively. The OR [ $95 \% \mathrm{Cl}$ ] of RA (vs. DM) for HIs, CVDs, fractures was 0.9 [0.8-1.1], 0.4 [0.3-0.6], 1.3 [1.0-1.7] after adjusting for baseline characteristics. Conclusions: This study revealed that patients with RA had significantly lower risk of CVDs than and similar risk of Hls and fractures to those with DM using health insurance database for the first time in Asia.

\section{References:}

[1] Arthritis Rheum, 2002;46:2287-93.

[2] Ann Rheum Dis, 2012:71:1524-29.

[3] Arthritis Res Ther, 2010;12:R154.

[4] Arthritis Rheum, 2009;61:1571-9.

Acknowledgements: This work was supported by the research grant from the Ministry of Health, Labour, and Welfare, Japan.

Disclosure of Interest: R. Sakai Grant/research support from: Ayumi Pharmaceutical Co., Chugai Pharmaceutical Co., Ltd., Eisai Co., Ltd., Nippon Kayaku Co., Ltd., Taisho Toyama Pharmaceutical Co., Ltd., Takeda Pharmaceutical Co., Ltd., Mitsubishi Tanabe Pharma Co., and Teijin Pharma Ltd.,Bristol-Meyers Squibb, S. Kasai: None declared, M. Tsutsumino Grant/research support from: Ayumi Pharmaceutical Co., Chugai Pharmaceutical Co., Ltd., Eisai Co., Ltd., Nippon Kayaku Co., Ltd., Taisho Toyama Pharmaceutical Co., Ltd., Takeda Pharmaceutical Co., Ltd., Mitsubishi Tanabe Pharma Co., and Teijin Pharma Ltd., H. Yamanaka Grant/research support from: Chugai Pharmaceutical Co. Ltd., Astellas Pharma Inc., Bristol-Meyers Squibb, AbbVie Japan Co. Ltd., Daiichi-Sankyo, Mitsubishi-Tanabe Pharma Corp., Takeda Pharmaceutical Co. Ltd., UCB Japan., Consultant for: Chugai Pharmaceutical Co. Ltd., Astellas, Bristol-Meyers Squibb, AbbVie Japan Co. Ltd., Daiichi-Sankyo, Mitsubishi-Tanabe Pharma Corp., Takeda Pharmaceutical Co. Ltd., UCB Japan., Speakers bureau: Chugai Pharmaceutical Co. Ltd., Astellas, Bristol-Meyers Squibb, AbbVie Japan Co. Ltd., Daiichi-Sankyo, Mitsubishi-Tanabe Pharma Corp., Takeda Pharmaceutical Co. Ltd., UCB Japan.,
N. Miyasaka: None declared, M. Harigai Grant/research support from: Ayumi Pharmaceutical Co., Chugai Pharmaceutical Co., Ltd., Eisai Co., Ltd., Nippon Kayaku Co., Ltd., Taisho Toyama Pharmaceutical Co., Ltd., Takeda Pharmaceutical Co., Ltd., Mitsubishi Tanabe Pharma Co., and Teijin Pharma Ltd.,Eisai,

DOI: 10.1136/annrheumdis-2017-eular.4558

\section{THU0167 ASSOCIATION OF BIOLOGIC ANTIRHEUMATIC THERAPY WITH THE RISK OF DEVELOPING TYPE 2 DIABETES IN ADULTS WITH RHEUMATOID ARTHRITIS: NEW EVIDENCE FROM REAL WORLD DATA}

S.K. Paul ${ }^{1}$, O. Montvida ${ }^{2}$, J.H. Best ${ }^{3}$, S. Gale ${ }^{3}$, A. Pethoe-Schramm ${ }^{4}$ K. Sarsour ${ }^{3}$. ${ }^{1}$ University of Melbourne, Melbourne; ${ }^{2}$ QIMR Berghofer Medical Research Institute, Brisbane, Australia: ${ }^{3}$ Genentech, South San Francisco, CA, United States; ${ }^{4}$ F. Hoffmann-La Roche, Basel, Switzerland

Background: While rheumatoid arthritis (RA) has been associated with the increased risk of developing type 2 diabetes mellitus (T2DM), few basic science studies have indicated the possible beneficial role of some biologic diseasemodifying antirheumatic drugs (bDMARDs), including the interleukin-6 (IL-6) based DMARDs, on insulin resistance in patients with RA.

Objectives: To evaluate the impact of treatment with bDMARDs, including the IL-6 inhibitors, on the probability of developing T2DM in a real world setting. Methods: From the Centricity Electronic Medical Records of GE Healthcare, a longitudinal cohort of 192,509 US adults (age $\geq 18$ years) with diagnosis of RA from January 2000 to April 2016 was selected. Patients were excluded if they had a prior history of diabetes, cancer and micro- or macro-vascular diseases at diagnosis of RA. Four mutually exclusive antirheumatic treatment groups (TGs) were identified by diagnosis date (Dx) and treatment initiation date (ID): tocilizumab (TCZ, $n=843$ ), TCZ+Other bDMARDs (TCZ+obDMARD, $n=2489$ ), non-TCZ other bDMARDs (obDMARD, $n=45,262)$ and no bDMARD $(n=143,915)$. Within the treatment groups, 142,225 patients had a minimum 6 months of exposure before development of T2DM or end of follow-up. Treatment-effects regression models were used to estimate the probabilities $(95 \% \mathrm{Cl})$ of developing T2DM during follow-up in the 4 TGs after adjusting and balancing with inverseprobability-weighted regression for various factors including age, sex, smoking status, body mass index, use of non-biologic DMARDs, use of statins, anaemia status and follow-up time post ID.

Results: At diagnosis, the 142,225 patients were on average 55 years old, $22 \%$ male, $71 \%$ white Caucasian, $13 \%$ with anaemia, and $32 \%$ obese with mean BMl of $29 \mathrm{~kg} / \mathrm{m}^{2}$. About $28 \% / 42 \%$ were using statins $/ \mathrm{MTX}$ at diagnosis or during follow-up before development of T2DM. During mean 4.6 years of follow-up from Dx, 2.6\%/2.6\%/5.3\%/5.8\% developed T2DM in the TCZ/TCZ+obDMARD/obDMARD/no bDMARD TGs. The adjusted probability of developing T2DM was 0.05 (95\% Cl: 0.04, 0.05) in no bDMARD group; with significantly lower probability of developing T2DM in TCZ [0.02 (95\% Cl: 0.01 , 0.04)], TCZ+obDMARD [0.03 (95\% Cl: $0.02,0.04)]$ and obDMARD [0.01 $(95 \%$ Cl: 0.01, 0.02)] groups (Table). Hypertension, higher BMI and Statin use were associated with significantly higher probability of developing T2DM by 0.25 (95\% Cl: $0.16,0.35), 0.08$ (95\% Cl: $0.07,0.08$ ) and 0.36 (95\% Cl: $0.27,0.47)$ respectively. Patients with anaemia had $8 \%$ higher likelihood of developing T2DM $(\mathrm{p}=0.13)$. Among those who received any $\mathrm{DDMARD}$, those who ever received TCZ had significantly lower probability of developing T2DM $(0.024,95 \% \mathrm{Cl}: 0.02$, $0.03)$, compared to those who were never exposed to TCZ therapy.

Table: The probability of developing T2DM, adjusted by age, sex, BMI, anaemia; balanced on hypertension, follow-up, obDMARDs and statin usage.

\begin{tabular}{|c|c|c|}
\hline & Probability $(95 \% \mathrm{CI})$ & Difference (95\% CI) \\
\hline No bDMARD & $0.046(0.045,0.048)$ & - \\
\hline obDMARD Only & $0.041(0.039,0.044)$ & $-0.005(-0.008,-0.002)$ \\
\hline TCZ Only & $0.025(0.006,0.043)$ & $-0.022(-0.04,-0.003)$ \\
\hline TCZ+obDMARD & $0.018(0.01,0.026)$ & $-0.029(-0.037,-0.02)$ \\
\hline \multicolumn{3}{|c|}{ Among those who received any bDMARDs } \\
\hline No TCZ & $0.046(0.044,0.049)$ & - \\
\hline TCZ & $0.023(0.017,0.029)$ & $-0.024(-0.03,-0.017)$ \\
\hline
\end{tabular}

Conclusions: This study indicates the possible beneficial role of IL-6 inhibitors (TCZ) in reducing the likelihood of developing T2DM among adults without major co-morbidities at diagnosis of RA.

Acknowledgements: Funding by F. Hoffmann-La Roche/Genentech.

Disclosure of Interest: S. Paul Grant/research support from: Therapeutic Innovations Australia, O. Montvida: None declared, J. Best Employee of: Genentech, S. Gale Employee of: Genentech, A. Pethoe-Schramm Employee of: F. Hoffmann-La Roche, K. Sarsour Employee of: Genentech DOI: 10.1136/annrheumdis-2017-eular.5222 